\title{
Flow velocity and cell pair number effect on current efficiency in plating wastewater treatment through electrodialysis
}

\author{
Kyung Jin Min, Joo Hyeong Kim, Eun Joo Oh, Jun Hee Ryu, Ki Young Park ${ }^{\dagger}$ \\ Department of Civil and Environmental Engineering, Konkuk University, Gwangjin-Gu, Seoul 05029, Republic of Korea
}

\begin{abstract}
Electrodialysis has been used for treating toxic substances such as heavy metals and minimizing secondary environmental pollution problems effectively. However, electrodialysis depends on the operating parameters as well as fluid dynamics and electrical properties. This study provides design elements for the treatment of heavy metal-containing wastewater by electrodialysis. We found that the limiting current density (LCD) is proportional but not completely linear to the diluate concentration over a threshold value. In contrast, it is linear to the linear flow velocity for the whole range. As the number of cell pairs increases, because linear flow velocity and LCD increase, the removal efficiency of heavy metals also increases. Therefore, for highly concentrated wastewater, increasing the linear flow velocity, the applied voltage, and the number of cell pairs can effectively improve removal efficiency. It was found that the current efficiency is as low as $17 \%$ when the removal efficiency of heavy metals exceeds $95 \%$. Thus, it is necessary to select an operating range that optimizes the operating and initial investment costs for the effective removal of heavy metals using electrodialysis.
\end{abstract}

Keywords: Current Efficiency, Electrodialysis, Heavy metals, Limiting Current Density, Linear Flow Velocity

\section{Introduction}

Climate change and excessive use of water resources have caused water shortage. To solve this problem, research has been focused on practical solutions with regard to treatment and reuse of wastewater [1-3]. In particular, electrodialysis has been used as a technique for minimizing secondary environmental pollution problems and treating toxic substances such as heavy metals effectively. Electrodialysis is a compact process that reduces the consumption of chemicals, energy, water, and land. Additionally, its operation cost can be reduced by minimizing the occurrence of chemical sludge and enabling automatic operation. Furthermore, the electrodialysis process can concentrate heavy metals. Electrodialysis, when combined with heavy metal extraction technologies, can thus efficiently recover heavy metals at a minimal cost [4-6].

Electrodialysis is a membrane separation technology that extracts salt ions from a solution by using an electric field and an ion exchange membrane, producing concentrated water containing salt ion and treated water with almost no salt ions.. The process occurs in a stack composed of the ion (cation/anion) exchange membrane, a spacer, a diluate and a concentrate channel. The system formed

This is an Open Access article distributed under the terms of the Creative Commons Attribution Non-Commercial License (http://creativecommons.org/licenses/by-nc/3.0/) which permits unrestricted non-commercial use, distribution, and reproduction in any medium, provided the original work is properly cited.

Copyright (C) 2021 Korean Society of Environmental Engineers by a cation exchange membrane, a concentrate containing cell, an anion exchange membrane, and a diluate containing cell is referred to as a cell pair. The factors affecting the efficiency of electrodialysis include influent, hydrodynamic, and electrical properties [2, 7-11].

Additionally, the performance of electrodialysis is determined by a set of fixed and variable process parameters, such as feed and product concentration, stack construction, ion exchange membrane permselectivity, flow velocity, current density, rates, etc. Therefore, to carry out electrodialysis efficiently, not only the operating parameters but also the components and characteristics should be optimized in terms of the overall cost [8, 12-14]. In particular, the process parameters directly affect the current efficiency and concentration polarization. In general, concentration polarization refers to the dissociation of water into $\mathrm{H}^{+}$and $\mathrm{OH}$ when the ion concentration on the surface of the cation and/or anion exchange membrane in the diluate cell is 0 . Here, because the anions (cations) are transported through the anion (cation) exchange membrane to the concentrate cell, the cations (anions) are concentrated in the boundary layer of the membrane surface to the diluate cell and increase at the surface facing the concentrate cell [8-10, 15-17]. Therefore, scaling may occur due to the deposition of metal hydrox-

Received December 18, 2019 Accepted April 13, 2020

${ }^{\dagger}$ Corresponding author

Email: kypark@konkuk.ac.kr

Tel: +82-2-450-3736 Fax: +82-2-450-3637 
ides on the surface of the ion exchange membrane [8, 18-19].

In general, when the set current density is reached, the cell resistance increases rapidly, and the voltage does not increase until the current density increases at the applied voltage. When the applied voltage exceeds a certain threshold called the limiting current density (LCD), the current density increases again. In electrodialysis, when the LCD is exceeded, the electrical resistance of the diluate rapidly increases because of the depletion of ions in the boundary layer of the membrane surface. In this situation, the current efficiency decreases [2-3]. Thus, the LCD is one of the most important design parameters to determine the efficiency of plant operation.

Therefore, to treat wastewater efficiently using electrodialysis, it is important to study the dependence of the LCD on the operating parameters [2-3, 16]. Most studies have focused on the use of electrodialysis as a seawater desalination process. In the case of studies on the separation of heavy metals such as copper and nickel, the separation efficiency and the ion LCD have been reported for wastewater of high concentration, containing single ions, or mixed with $\mathrm{NaCl}$ [19-21]. However, these values are difficult to use as a design factor because of the great differences from actual wastewater. In this context, this study aims to provide design factors for the treatment of plating wastewater containing low concentrations of heavy metals using an electrodialysis process.

The specific objectives of this study were: (a) to investigate the correlation between heavy metal concentration and LCD at constant linear flow velocity; (b) to correlate the LCD with the linear flow velocity at constant heavy metal concentration; (c) to measure the separation and current efficiency of heavy metals according to the number of cell pairs.

\section{Material and Methods}

\subsection{Wastewater}

The properties of wastewater from electroplating facilities were analyzed to determine copper and nickel concentrations. The analysis revealed that the copper concentration ranged from 19 to 250 $\mathrm{mg} / \mathrm{L}$ and the nickel one from 18 to $150 \mathrm{mg} / \mathrm{L}$. The electrical conductivity ranged from 2,500 to $7,000 \mu \mathrm{S} / \mathrm{cm}$ and $\mathrm{pH}$ from 2.0 to 2.4. Nickel of synthetic plating wastewater was prepared using nickel (II) sulfate hexahydrate $\left(\mathrm{NiSO}_{4} \cdot 6 \mathrm{H}_{2} \mathrm{O}\right.$, Sigma-Aldrich, USA), and copper was prepared using copper (II) sulfate pentahydrate
( $\mathrm{CuSO}_{4} \cdot 5 \mathrm{H}_{2} \mathrm{O}$, Sigma-Aldrich, USA). The $\mathrm{pH}$ was measured after preparing $10 \%$ sulfuric acid $\left(\mathrm{H}_{2} \mathrm{SO}_{4}\right.$, Sigma-Aldrich, USA) using distilled water. Table 1 summarizes the concentrations of synthetic plating wastewater.

\subsection{Materials}

The most important factor in determining the performance of an electrodialysis process is the ion exchange membrane. The ion exchange membrane can be regarded as a film of ion exchange resin. The properties of ion exchange membranes are determined by different parameters, such as the density of the polymer network, the hydrophobic or hydrophilic character of the matrix polymer, the type and concentration of the fixed charges in the polymer, and the morphology of the membrane itself. The membranes should have low electrical resistance, good mechanical, high chemical, thermal stability, high permselectivity, and low production costs [9].

In this study, we used a Neosepta CMX-SB and AMX-SB from ASTOM (Tokyo, Japan) as cationic and anionic ion exchange membrane, respectively. Their physical properties are reported in Table 2. The ion exchange membrane was immersed in distilled water for $1 \mathrm{~h}$ at room temperature before use. At the end of the experiment, to remove the salt attached to the ion exchange membrane, it was immersed in $0.36 \% \mathrm{H}_{2} \mathrm{SO}_{4}$ and $1.22 \% \mathrm{Na}_{2} \mathrm{SO}_{4}$ (Sigma-Aldrich, USA) for $1 \mathrm{~h}$. The ion exchange membrane used in the experiment was used after immersion for $24 \mathrm{~h}$ in the solution to be used in the experiment at $25 \pm 1^{\circ} \mathrm{C}$.

\subsection{Experimental Setup}

The electrodialysis system used in this experiment (CJ-S3, ChangJotechno Co. Ltd., Korea) consists of a dilution/concentration/electrolyte solution tank, ion exchange stack, diluate/concentrate/electrolyte feed pump, and power supply (Fig. 1). The capacity of the solution tanks, made of PVC, is $0.5 \mathrm{~L}$.

The ion exchange stack is $115 \mathrm{~mm}(\mathrm{~W}) \times 225 \mathrm{~mm}(\mathrm{H})$, and the distance between the cation and anion exchange membrane is $0.73 \mathrm{~mm}$, filled by a planar diluate/concentrate/net-like spacer. The effective surface area of the anion/cation exchange membrane was $55.5 \mathrm{~cm}^{2}$. The flow paths in the diluate and concentrate cell of the ion exchange stack are independent and are maximized by design. In particular, the net-like spacers induce a zigzag flow, providing better turbulent flows and reducing concentration polarization phenomena [9].

Table 1. Properties of the Synthetic Wastewater

\begin{tabular}{lccc}
\hline Salt solution (mg/L) & Main cation & Main anion & Linear flow velocity (cm/s) \\
\hline $\mathrm{CuSO}_{4}(20)+\mathrm{NiSO}_{4}(20)$ & $\mathrm{Cu}^{2+}, \mathrm{Ni}^{2+}$ & $\mathrm{SO}_{4}{ }^{2-}$ & $1.1,1.6,1.7,2.0$ \\
$\mathrm{CuSO}_{4}(100)+\mathrm{NiSO}_{4}(100)$ & $\mathrm{Cu}^{2+}, \mathrm{Ni}^{2+}$ & $\mathrm{SO}_{4}{ }^{2-}$ & $1.1,1.6,1.7,2.0$ \\
$\mathrm{CuSO}_{4}(200)+\mathrm{NiSO}_{4}(200)$ & $\mathrm{Cu}^{2+}, \mathrm{Ni}^{2+}$ & $\mathrm{SO}_{4}{ }^{2-}$ & $1.1,1.6,1.7,2.0$ \\
\hline
\end{tabular}

Table 2. Properties of the ASTOM ion Exchange Membranes Used [12]

\begin{tabular}{cccccc}
\hline Ion Membrane Exchange & Type & $\begin{array}{c}\text { Thickness } \\
(\mathbf{m m})\end{array}$ & $\begin{array}{c}\text { Electrical resistance } \\
\left(\mathbf{\Omega} \mathbf{~ c m}^{\mathbf{2}}\right)\end{array}$ & $\begin{array}{c}\text { Burst strength } \\
\mathbf{( k P a )}\end{array}$ & $\begin{array}{c}\text { Counterion } \\
\text { transport number }\end{array}$ \\
\hline AMX-SB & Strongly acidic & 0.14 & 2.4 & 30 & $>0.98$ \\
CMX-SB & Strongly basic & 0.17 & 3.0 & 40 & $>0.98$ \\
\hline
\end{tabular}



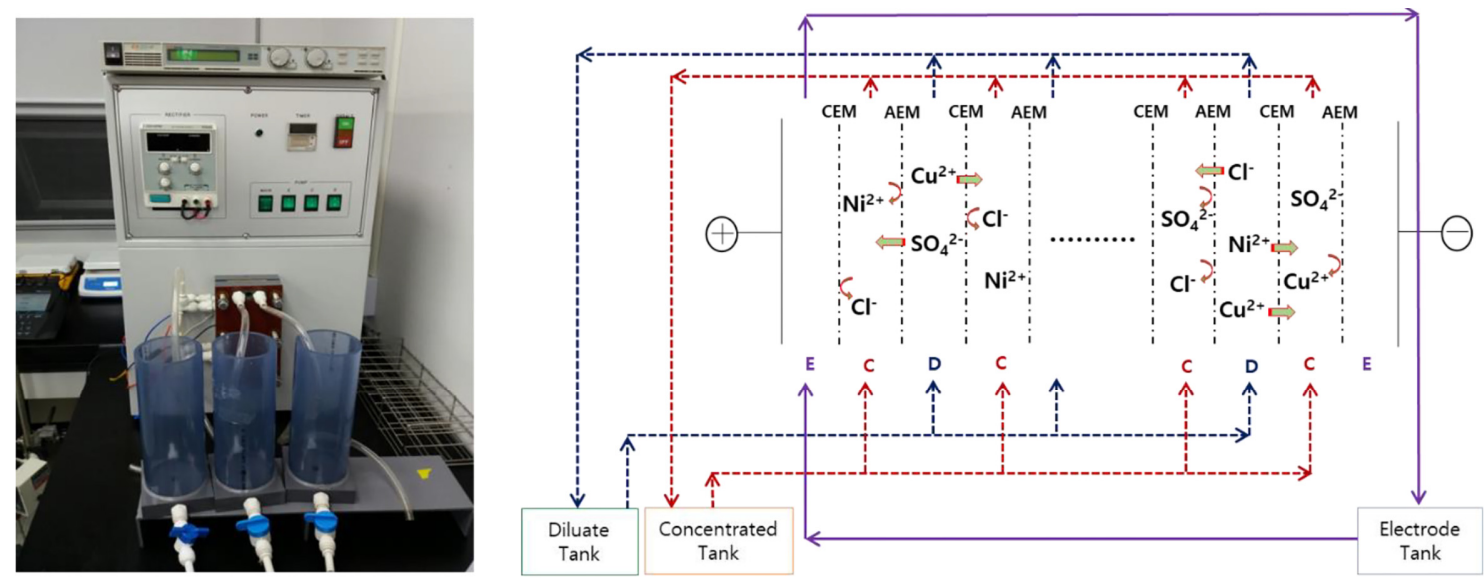

Fig. 1. Photograph and schematic diagram of the electrodialysis system.

At both ends of the stack are the cathode and anode. Their electrode size was $45 \mathrm{~mm}(\mathrm{~W}) \times 105 \mathrm{~mm}(\mathrm{H}) \times 2 \mathrm{~mm}(\mathrm{D})$, and their titanium base was platted with a solution containing platinum and ruthenium to prevent corrosion.

To prevent leakage in each cell, a silicone rubber seal was inserted, and a steel block was installed at the top and bottom of the cell to press the ion exchange membrane and the spacer together, and then screwed. The power supply used in the experiment (P3030, Advantek Co. Ltd., Korea) can supply potential and direct current up to $30 \mathrm{~V}$ and $3 \mathrm{~A}$, respectively.

\subsection{Operating Conditions}

A laboratory-scale electrodialysis system was used to measure the LCD as a function of the $\mathrm{Cu}$ and $\mathrm{Ni}$ concentrations. Using an ion exchange stack consisting of 5 pairs, the LCD of synthetic wastewater, prepared with concentrations of $\mathrm{CuSO}_{4}$ and $\mathrm{NiSO}_{4}$ of 20 , 100, and $200 \mathrm{mg} / \mathrm{L}$, was measured. Current and resistance were measured at each potential. The potential was increased by $1 \mathrm{~V}$ from 1 to $10 \mathrm{~V}$, and by $2 \mathrm{~V}$ from 10 to $30 \mathrm{~V}$. The current and resistance were measured after 5 minutes of stabilization at each step [22]. By changing the number of the pairs of membranes to $1,3,5$, and 9 , the effect of the linear flow velocity of the membrane on the LCD was measured. Here, the linear flow velocity of both the diluate and concentrate was controlled. Additionally, using synthetic wastewater with a $20 \mathrm{mg} / \mathrm{L}$ concentration of $\mathrm{CuSO}_{4}$ and $\mathrm{NiSO}_{4}$ and according to the LCD of each pair, the copper and nickel concentrations, electrical conductivity, and current over time were measured. The electrolyte used was a $4 \%$ (w/w) $\mathrm{Na}_{2} \mathrm{SO}_{4}$ solution [18, 23].

\subsection{Analytical Methods}

Copper and nickel concentrations were measured using inductively coupled plasma optical emission spectroscopy (ICP-OES, ICP-6000, Thermo Fisher Scientific Inc., USA) and according to method EN ISO 11885:2007. The samples were filtered by a syringe equipped with polyethersulfone filters with an average pore diameter of 0.45 $\mu \mathrm{m}$ and then acidified to $2 \%$ with concentrated HCl. Dilutions of the multielement standards solution 6 for ICP (Sigma-Aldrich Co., LLC., USA) were used for calibration, using a six-point function with blank, 0.1, 1.0, 5.0, 10.0 and $20.0 \mathrm{mg} / \mathrm{L}$. Samples were diluted with $2 \% \mathrm{HCl}$ if they contained higher concentrations than the endpoint of the calibration function. The multielement standards solution was initially acidified to $1 \%$ with concentrated $\mathrm{HCl}$ and dilutions were made with a $2 \% \mathrm{HCl}$ solution. The analytical wavelengths of metal ions in this study was $\mathrm{Ni}(231.60 \mathrm{~nm})$ and $\mathrm{Cu}$ (324.75 nm). The ion separation efficiencies were obtained using the changes in the concentration of copper and nickel and the conductivity of the diluate during electrodialysis. The conductivity of all samples was measured at regular intervals using an Orion 5 Star instrument (Thermo Fisher Scientific Inc., USA).

The decrease in conductivity over time in the dilution tank was determined using

$$
\frac{C_{t}}{C_{o}}=e^{-k_{1} t}
$$

where $C_{o}$ and $C_{t}$ are the conductivity $(\mu \mathrm{S} / \mathrm{cm})$ of the diluate at the beginning of the experiment and at time $t$, respectively, and $k_{1}$ is a first order constant [24].

In general, the LCD is known to be proportional to the mass transfer coefficient and ion concentration of the diluate as

$$
\mathrm{LCD}=k C^{n}
$$

which can be rewritten as $[8,25]$

$$
\operatorname{lnLCD}=\ln k+n \ln C
$$

Here, $k$ is the mass transfer coefficient $(\mathrm{m} / \mathrm{s})$ and $C$ is the ion molar concentration $\left(\mathrm{mol} / \mathrm{m}^{3}\right)$ in the diluate.

The flow rate in an electrodialysis system can be expressed as [25]

$$
\mathrm{Q}=u \cdot \Delta \cdot w \cdot N
$$

where $Q$ is the volumetric flow rate $\left(\mathrm{m}^{3} / \mathrm{s}\right)$,is the theoretical linear flow velocity $(\mathrm{m} / \mathrm{s}), \Delta$ is the thickness of unit cell $(\mathrm{m}), w$ is the width of the diluate cell (m), and $N$ is the total number of cell pairs. 
In this experiment, the linear flow velocity was changed by supplying the maximum flow rate to each cell pair. The mass transfer coefficientcan generally be expressed as a nonlinear function of the linear flow velocity:

$$
k=a\left(v_{d}\right)^{b}
$$

Here, $v_{d}$ is the linear flow velocity $(\mathrm{cm} / \mathrm{s})$ of the diluate, and $a$ and $b$ are empirical parameters.

Using Eq. (5), a simple empirical equation that gives reasonable results for the LCD as a function of concentration and linear flow velocity can be found, as seen by equation (6) and (7):

$$
\begin{gathered}
\mathrm{LCD}=k C=a\left(v_{d}\right)^{b} C^{n} \\
a\left(v_{d}\right)^{b}=a e^{b \ln \left(v_{d}\right)}
\end{gathered}
$$

Because the charge passes through all the cell pairs connected in series, the current efficiency can be expressed as $[9,15,25]$

$$
\mathrm{I}=\frac{z F Q C_{S}^{\Delta}}{\zeta N}
$$

where I is the total electric current passing through the stack (A), $C_{s}^{\Delta}$ is the concentration difference between the feed and product solutions obtained during the operation $\left(\mathrm{mol} / \mathrm{m}^{3}\right), \zeta$ is the current utilization, $z$ the valence number, $F$ the Faraday constant $(\mathrm{C} / \mathrm{mol})$, and $Q$ and $N$ are the same as in Eq. (4).

\section{Results and Discussion}

\subsection{Dependence of the LCD on Metal Concentration}

In physical models, the LCD is empirically correlated to the flow velocity and bulk concentration of the diluate [16]. Some studies have reported LCD equations that depend on the hydrodynamic conditions, including flow velocity, and that include coefficients that are constant or functions of the flow velocity [15, 17]. However,

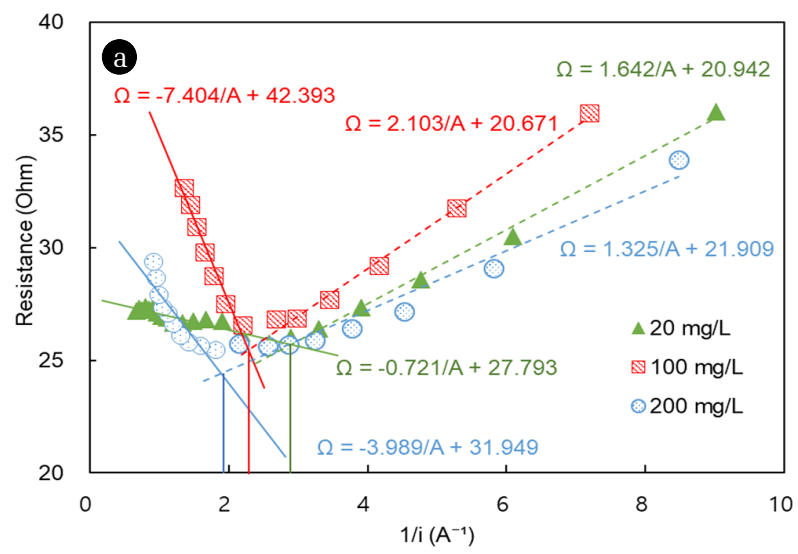

Fig. 2. (a) Resistance as a function of the inverse of the current and (b) Experimental and theoretical limiting current density. most of them are the result of experiments performed on electrochemical cells under very specific conditions, and therefore require correction. Moreover, it is very difficult to determine the LCD in industrial electrodialysis systems because of the varying membrane thicknesses [26]. Therefore, the LCD must be approximated or measured using a reproducible electrodialysis system [16].

To analyze the dependence of the LCD on the diluate concentration, we measured the LCD at copper and nickel concentrations of 20,100 and $200 \mathrm{mg} / \mathrm{L}$. In the electrodialysis process, the maximum current per unit area of the membrane must be maintained as high as possible, though the operational level is limited by polarization [2]. The LCD is determined from the graph of the inverse of the current as a function of the cell resistance (Fig. 2(a)). Because the LCD is a current with zero ion concentration at the surface of the ion exchange membrane, the current required for ion depletion increases as the electrolyte concentration in the bulk layer increases [8]. Therefore, the LCD is the point where the slope of the potential/current changes because of water dissociation on the surface of the ion exchange membrane (Fig. 2(b)).

In this study, for copper and nickel concentration of 20, 100, and $200 \mathrm{mg} / \mathrm{L}$ in the diluate, the LCD increased from 14.1 to 16.4 and $25.0 \mathrm{~A} / \mathrm{m}^{2}$, respectively, under the same linear flow velocity conditions (Fig. 3(a)). However, a linear relationship cannot be assumed at all concentrations. In fact, at low electrolyte concentrations, the LCD and the coefficients can be affected by high electrical resistivity and by the diffusion coefficient in solution [8]. According to equation (3), it is reasonable to measure only at concentrations above $1 \mathrm{~mol} / \mathrm{m}^{3}$, because below this value the LCD is zero. Because the measured LCD depends on the ion concentration in the diluate, a proper choice of the concentration range is necessary to determine the LCD.

\subsection{Dependence of the LCD on the Llinear Flow Velocity}

The relationship between the LCD and linear flow velocity was investigated by changing the number of membrane pairs under the same metal concentration.

The LCD increased with increasing linear flow velocity (Fig. 3(b)). The coefficients $a$ and $b$ were measured 7.645 and 1.318 , respectively, in the $1-2 \mathrm{~cm} / \mathrm{s}$ linear velocity range.

Some researchers measured coefficients $a$ and $b$ at different linear

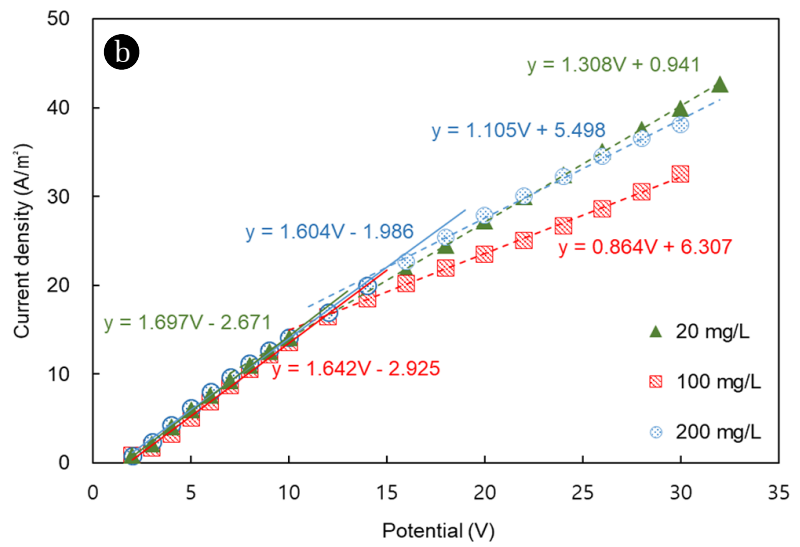



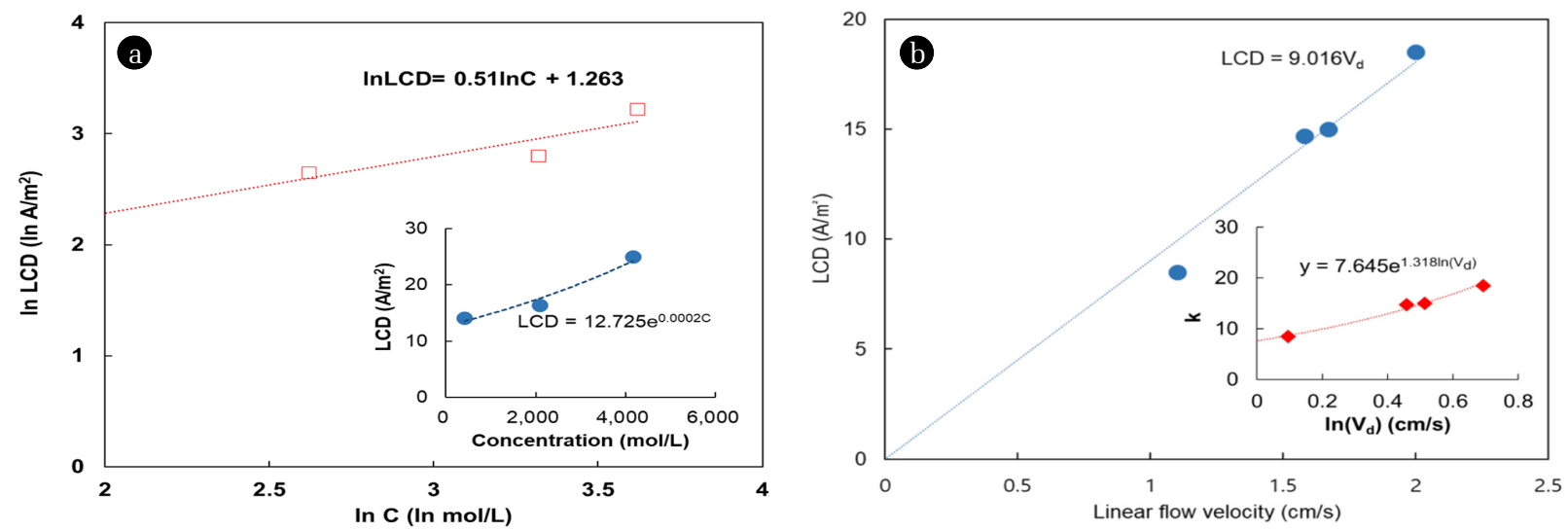

Fig. 3. (a) LCD as a function of the molar concentration and (b) The linear flow velocity of the diluate.

flow velocities and $\mathrm{NaCl}$ concentrations. They report that coefficient $b$ is affected by the fluid properties, including the linear feed flow rate, whereas coefficient $a$ is related to the cell composition, including the ion transport through the ion exchange [27-28]. In contrast, for well-mixed solutions, the linear flow velocity did not significantly affect the transport of electrolyte through the membrane [8, 29].

\subsection{Dependence of the Separation Efficiency on the Number of Cell Pairs}

The separation efficiency of copper and nickel was measured as a function of the number of cell pairs to evaluate the applicability of electrodialysis to heavy metals. The change in conductivity in the electrodialysis process was used to indirectly identify desalination. Electrodialysis has been reported to be more economical in the $2,000-10,000 \mu \mathrm{S} / \mathrm{cm}$ conductivity range and to have better ion removal efficiency than nanofiltration $[1,30]$. Thus, electrodialysis should efficiently separate heavy metals contained in plating wastewater, because the wastewater has a conductivity of approximately $2,500 \mu \mathrm{S} / \mathrm{cm}$.

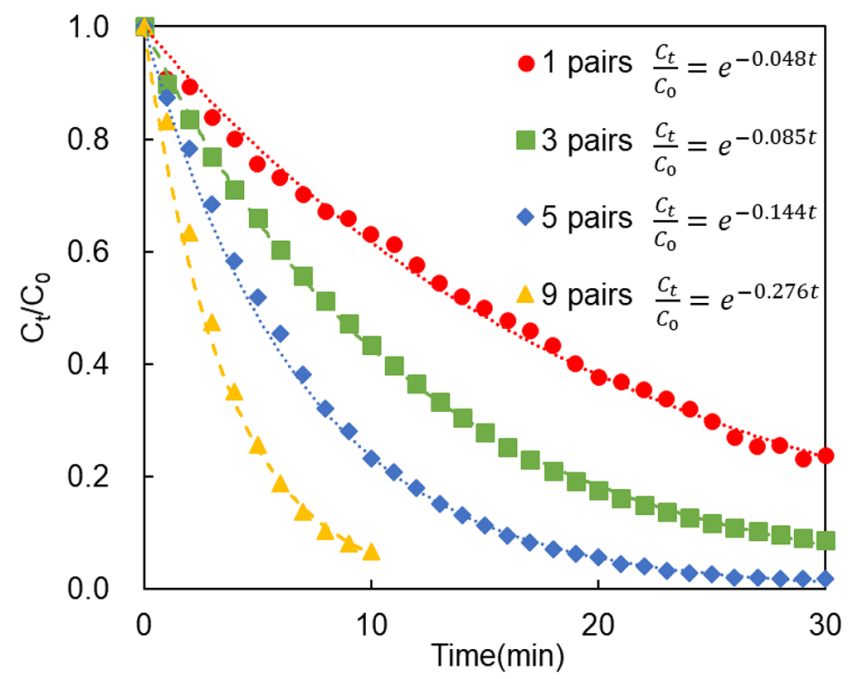

Fig. 4. Conductivity as a function of time for different numbers of ion exchange membrane pairs.
In the electrodialysis process, when an electric potential is applied, the anions and cations are accumulated in a concentrate cell by the ion exchange membrane. The applied voltage is not only crucial for the process to occur but also determines the separation efficiency. Therefore, the ion separation efficiency in electrodialysis can be measured by regression analysis of the experimental data as a first-order constant.
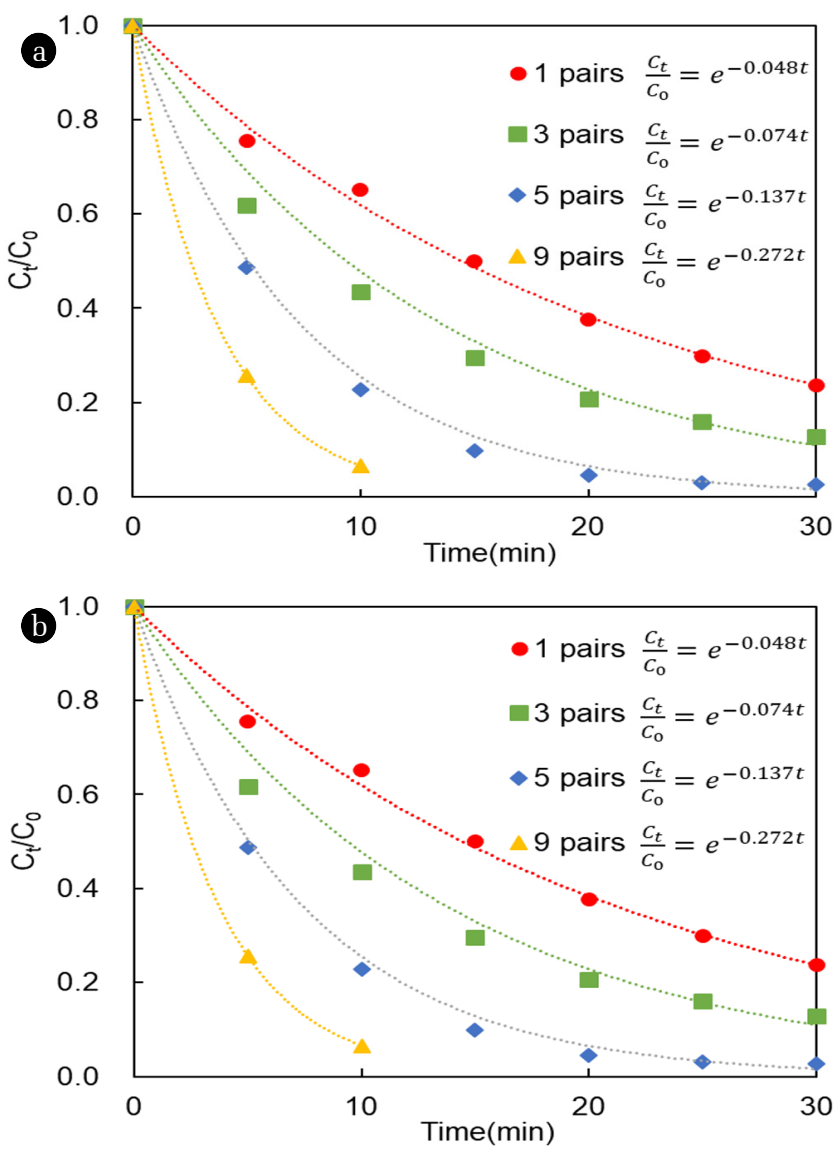

Fig. 5. Concentration of (a) Copper and (b) Nickel as a function of time for different numbers of ion-exchange membrane pairs. 
Fig. 4 shows the conductivity as a function of the applied potential for each cell pair. As the number of cell pairs increases, the linear flow velocity and the LCD increase. Therefore, the ion transfer rate also increases, resulting in an increase in reaction rate and, in turn, in a reduction of the time required for separation.

However, the separation rates of nickel and copper were nearly the same under all conditions (Fig. 5). This is because both copper and nickel are divalent ions [31]. The change in conductivity is almost the same as the change in copper and nickel concentration, which can be indirectly used to evaluate the degree of desalination and separation efficiency.

\subsection{Dependence of the Current Efficiency on the Number of Cell Pairs}

The total cost of electrodialysis is the sum of the initial investment and the energy and maintenance costs. The energy costs increase linearly as the current density increases, whereas the investment costs decrease. Therefore, there is a value of the current density that optimizes the total cost.

Measuring the current efficiency under different experimental conditions, we found that the current efficiency decreased with increases in the number of cell pairs and operating time. However, in the case of 5 pairs and 9 pairs, the current efficiency was approximately $16 \%$ and $17 \%$, respectively, when the efficiency of heavy metals separation exceeded 95\% (Fig. 6). Therefore, the fewer the cell pairs, the higher the efficiency of the current, because the ion separation performance decreases at each incremental step (pair). Thus, the efficiency of the current is a measure of the electric power used for ion separation.

The loss of current efficiency is largely determined by the selectivity of the membrane and its scaling, e.g. in water movement, current leakage, and failing because of osmosis and electroosmosis. The selectivity of the ion-selective membrane strongly depends on the concentration of salt in the external solution. When this increases, the intensity of the diffusion flux from the external solution into the membrane increases. The amount of water transported

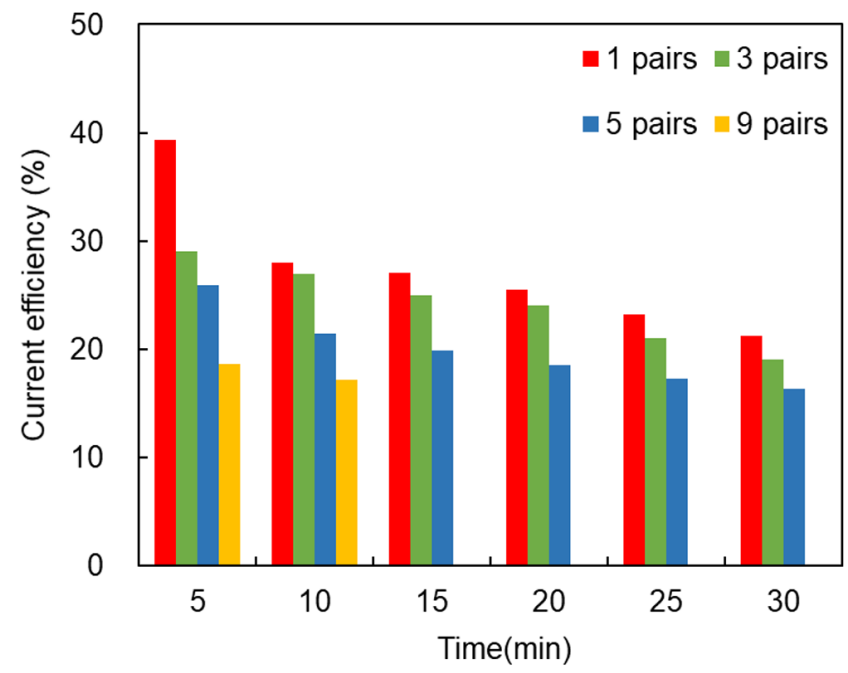

Fig. 6. Current efficiency for different numbers of ion exchange membrane pairs. because of electroosmosis is proportional to the amount of salt transported from the diluate to concentration cell, i.e. It is directly proportional to the electric current (charge) passing through the membranes.

Generally, exceeding the LCD causes concentration polarization at the surface of the ion exchange membrane [2, 32]. In electrodialysis, exceeding the LCD results in the electrical resistance of the solution increasing, leading to a drastic drop in the efficiency of the process. Additionally, the dissolution of water can cause a rapid change in $\mathrm{pH}$ in the solution on the ion exchange membrane surface. This change in $\mathrm{pH}$ can lead to the deposition of metal hydroxides at the surface of the ion exchange membrane, resulting in scaling [8]. If the range of the operating $\mathrm{pH}$ of the membrane is small, the membrane may be damaged, resulting in lower removal and current efficiency [2]. Additionally, the current efficiency can be reduced by the formation of additional electrically conductive paths between the manifold, the channels inside the stack, and the external electrodes [8-9].

\section{Conclusions and Summary}

In electrodialysis, the number of cell pairs and the applied voltage are crucial operating factors that determine the initial investment cost, energy consumption, and efficiency of metal ions separation. This study provided design elements to treat wastewater containing copper and nickel using electrodialysis.

The LCD was found to be proportional to the dilute concentration, though not in the whole range. In contrast, a linear relationship was found in the whole range of the linear flow velocity. In the 1-2 cm/s linear velocity range, coefficientsandwere measured 7.645 and 1.318 , respectively. The optimum flow velocity and number of cell pairs in this experiment were $2.0 \mathrm{~cm} / \mathrm{s}$ and 9 , respectively. There was no significant difference in the separation rate of copper and nickel in the wastewater containing them both. Therefore, for highly concentrated wastewater, increasing the linear flow rate and applied voltage can effectively reduce the treatment time.

Regarding the efficiency of the current, because the ion transport depends on the charge supplied, according to Faraday's law, as the processing efficiency increased, the current efficiency decreased. When the separation efficiency was over 95\%, the current efficiency was as low as $16-17 \%$. This may be because of the selectivity of the membrane, the movement of water caused by osmosis and electroosmosis, current leakage, scaling of the membrane or failure. Because the current density is the most important factor in determining operating and initial investment costs, a proper operating LCD range is of high utility for applications.

\section{Acknowledgment}

This subject is supported by Korea Ministry of Environment (MOE) as "Technologies for the Risk Assessment \& Management Program (2017000140006)" and the "Human Resource Program (Grant No. 20194010201790)" of the Korea Institute of Energy Technology Evaluation and Planning (KETEP) grant funded by the Ministry of Trade, Industry \& Energy (MOTIE) of the Republic 
of Korea. This article was presented at the 2019 International Desalination Workshop (IDW2019) held on 28-30 August 2019, Jeju, Korea.

\section{Author Contributions}

K.J.M. (Ph.D.) checked all experimental results and wrote a manuscript. J.H.K. (M.D student) conducted all the experiments. E.J.O. (M.D student) conducted all the experiments. J.H.R. (Ph.D.) supported writing manuscript. K.Y.P. (Ph.D.) approved all experimental results and modified the manuscript.

\section{References}

1. Fu F, Wang Q. Removal of heavy metal ions from wastewaters: a review. J. Environ. Manage. 2011;92:407-418.

2. Bernardes AM, Rodrigues MAS, Ferreira JZ. Electrodialysis and water reuse. $1^{\text {st }}$ ed. Berlin: Springer-Verlag; 2016.

3. Min KJ, Choi SY, Jang D, Lee J, Park KY. Separation of metals from electroplating wastewater using electrodialysis. Energ. Sour. A 2019;41:1-10.

4. Zhang L, Xie L, Lin H, Gao C. Progress and prospects of seawater desalination in China. Desalination 2005;182:13-18.

5. Al KA, Renne D, Kazmerski L. Technical and economic assessment of photovoltaic-driven desalination systems. Renew. Energ. 2010;35:323-328.

6. Walker WS, Kim Y, Lawler DF. Treatment of model inland brackish groundwater reverse osmosis concentrate with electrodialysis-Part I: sensitivity to superficial velocity. Desalination 2014;344:152-162.

7. Lee J, Cha HY, Min KJ, Cho J, Park KY. Electrochemical nitrate reduction using a cell divided by ion-exchange membrane. Membr. Water Treat. 2018;9:189-194.

8. Lee HI, Strathmann H, Moon SH. Determination of the limiting current density in electrodialysis desalination as an empirical function of linear velocity. Desalination 2006;190:43-50.

9. Strathmann H. Electrodialysis, a mature technology with a multitude of new applications. Desalination 2010;264:268-288.

10. Firdaous L, Malériat JP, Schlumpf JP, Quéméneur F. Transfer of monovalent and divalent cations in salt solutions by electrodialysis. Sep. Sci. Technol. 2007;42:931-948.

11. Choi EY, Choi JH, Moon SH. An electrodialysis model for determination of the optimal current density. Desalination 2003;153: 399-404.

12. Geraldes V, Afonso MD. Limiting current density in the electrodialysis of multi-ionic solutions. J. Memb. Sci. 2010;360:499-508.

13. Murthy ZVP, Chaudhari LB. Application of nanofiltration for the rejection of nickel ions from aqueous solutions and estimation of membrane transport parameters. J. Hazard. Mater. 2008;160:70-77.

14. Caprarescu S, Purcar V, Vaireanu DI. Separation of copper ions from synthetically prepared electroplating wastewater at different operating conditions using electrodialysis. Sep. Sci. Technol. 2012;47:2273-2280.

15. Lee HJ, Sarfert F, Strathmann H, Moon SH. Designing of an electrodialysis desalination plant. Desalination 2002;142: 267-286.

16. Cerva ML, Gurreri L, Tedesco M, et al. Determination of limiting current density and current efficiency in electrodialysis units. Desalination 2018;445:138-148.

17. Tanaka Y. Limiting current density of an ion-exchange membrane and of an electrodialyzer. J. Memb. Sci. 2005;266:6-17.

18. Bruggen BV, Koninckx A, Vandecasteele C. Separation of monovalent and divalent ions from aqueous solution by electrodialysis and nanofiltration. Water Res. 2004;38:1347-1353.

19. Dermentzis K. Removal of nickel from electroplating rinse waters using electrostatic shielding electrodialysis/electrodeionization. J. Hazard. Mater. 2010;173:647-652.

20. Dydoa P, Babilasa D, Jakóbik KA, Franczakb A, Nyczb R. Study on the electrodialytic nickel concentration from electroplating industry waste. Sep. Sci. Technol. 2018;53:1241-1248.

21. Benvenuti T, Krapf RS, Rodrigues MAS, Bernardes AM, Zoppas FJ. Recovery of nickel and water from nickel electroplating wastewater by electrodialysis. Sep. Purif. Technol. 2014;129: 106-112.

22. Cowan DA, Brown JH. Effect of turbulence on limiting current in electrodialysis cells. Ind. Eng. Chem. 1959;51:1445-1448.

23. Ji ZY, Chen QB, Yuan JS, Liu J, Zhao YY, Feng WX. Preliminary study on recovering lithium from high $\mathrm{Mg}^{2+} / \mathrm{Li}^{+}$ratio brines by electrodialysis. Sep. Purif. Technol. 2017;172:168-177.

24. Valerdi PR, Berna ALM, Ibáñez MJA. Determination of the working optimum parameters for an electrodialysis reversal pilot plant. Sep. Sci. Technol. 200;35:651-666.

25. Brauns E, Wilde WD, Bosch BV, Lens P, Pinoy L, Empsten M. On the experimental verification of an electrodialysis simulation model for optimal stack configuration design through solver software. Desalination 2009;249:1030-1038.

26. Güvenç A, Karabacakolu B. Use of electrodialysis to remove silver ions from model solutions and wastewater. Desalination 2005;172:7-17.

27. Balmann HR, Sanchez V. Continuous-flow electrophoresis: a separation criterion applied to the separation of model proteins. J. Chromatogr. A. 1992;594:351-359.

28. Rubia Á, Rodríguez M, Prats D. pH, Ionic strength and flow velocity effects on the NOM filtration with $\mathrm{TiO}_{2} / \mathrm{ZrO}_{2}$ membranes. Sep. Purif. Technol. 2006;52:325-331.

29. Aider M, Brunet S, Bazinet L. Effect of solution flow velocity and electric field strength on chitosan oligomer electromigration kinetics and their separation in an electrodialysis with ultrafiltration membrane (EDUF) system. Sep. Purif. Technol. 2009;69:63-70.

30. Norton B, Scherrenberg DSM, Lier JB. Reclamation of used urban waters for irrigation purposes-a review of treatment technologies. J. Environ. Manage. 2013;122:85-98.

31. Zhang YH, Liu FQ, Zhu CQ, et al. Multifold enhanced synergistic removal of nickel and phosphate by a (N, Fe)-dual-functional bio-sorbent: Mechanism and application. J. Hazard. Mater. 2017;329:290-298.

32. Krol JJ, Wessling M, Strathmann H. Chronopotentiometry and overlimiting ion transport through monopolar ion exchange membranes. J. Memb. Sci. 1999;162:155-164. 